\title{
Correction: Erhebungen zur Anwendung von chemischen Pflanzenschutzmitteln in Zuckerrüben
}

\section{Dietmar Roßberg ${ }^{1} \cdot$ Nelia Aeckerle $^{2} \cdot$ Nicol Stockfisch $^{2}$}

Online publiziert: 2. Februar 2018

๑) Springer-Verlag GmbH Deutschland, ein Teil von Springer Nature 2018

\section{Correction:}

\section{Gesunde Pflanzen (2017)}

https://doi.org/10.1007/s10343-017-0389-5

Gesunde Pflanzen 69:59-66, 2017.

S. 64, Diskussion, rechte Spalte, 3. Absatz, Zeile 1 folgende In diesem Satz wurden die Zahlen vertauscht. Der Satz lautet korrigiert:

Der höchste Behandlungsindex mit 4,17 ergab sich ebenso wie die höchste Behandlungshäufigkeit mit 5,23 für das Jahr 2012.

Die Online-Version des Originalartikels ist unter https://doi.org/ 10.1007/s10343-017-0389-5 zu finden.

\section{Dietmar Roßberg}

dietmar.rossberg@julius-kuehn.de

1 Institut für Strategien und Folgenabschätzung, Julius Kühn-Institut, Bundesforschungsinstitut für Kulturpflanzen, Stahnsdorfer Damm 81, 14532 Kleinmachnow, Deutschland

2 Institut für Zuckerrübenforschung, Holtenser Landstraße 77, 37079 Göttingen, Deutschland 